\title{
Agriculture Information Service Built on Geospatial Data Infrastructure and Crop Modeling
}

\author{
Kiyoshi Honda \\ Chubu University \\ Aichi, Japan \\ Tel: +81-568-51-1111 \\ hondak@isc.chubu.ac.jp \\ Apichon Witayangkurn \\ University of Tokyo \\ Tokyo, Japan \\ Tel:+81-3-5452-6412 \\ apichon@iis.u-tokyo.ac.jp
}

\author{
Amor V.M. Ines \\ IRI, Columbia University \\ New York, USA \\ Tel: +1-845-680-4490 \\ ines@iri.columbia.edu
}

\author{
Akihiro Yui \\ IHI Corporation \\ Tokyo, Japan \\ Tel:+81-3-6204-7800 \\ akihiro_yui@ihi.co.jp
}

\begin{abstract}
An agricultural information service platform, called FieldTouch, is being built and tested on geospatial data infrastructure and crop modeling framework. More than 100 farmers in Hokkaido, Japan, have been participating on this development and are utilizing the services for optimizing their daily agricultural practices, e.g., planning and targeting areas where to apply fertilizer more to enhance homogeneity of growth and robustness of crops in their fields.

FieldTouch integrates multi-scale sensor data for field monitoring, provides functionality for recording agricultural practices, then supports farmers in decision making e.g., fertilizer management. RapidEye satellite images are being used for monitoring vegetation status updated every two weeks. Field sensor data from 25 nodes record soil moisture and temperature data at different soil depths, and suites of meteorological variables e.g., rainfall, minimum and maximum temperature, solar radiation, wind, etc. every 10 minutes. Data from national weather observation network, AMeDAS, is also a source of daily weather data. We used "cloudSense" sensor backend service that serves meta-data and data to FieldTouch via a standard web service called SOS (Sensor Observation Service), which brought great flexibility and enhanced automation of system's operation.
\end{abstract}

Using agronomic data from experimental station, the cultivar parameters (genetic coefficients) of a local wheat variety were calibrated for the DSSAT (Decision Support System for Agrotechnology Transfer) crop model using data assimilation. These were built in a web-based DSSAT wheat crop model called Tomorrow's Wheat (TMW) where in a user can explore the

Permission to make digital or hard copies of part or all of this work for personal or classroom use is granted without fee provided that copies are not made or distributed for profit or commercial advantage and that copies bear this notice and the full citation on the first page. Copyrights for third-party components of this work must be honored. For all other uses, contact the Owner/Author.

Copyright is held by the owner/author(s).

IWWISS '14, Sep 01-02 2014, Saint Etienne, France

ACM 978-1-4503-2747-3/14/09.

http://dx.doi.org/10.1145/2637064.2637094 effects of timing of sowing at a given climatic condition, soil and crop management. TMW accesses long-term weather data from the on-line observation station up to the most recent archive, parameterize a built-in weather generator, then generate 100 weather scenarios then runs the wheat model at the chosen planting date, then two weeks, and one week before and after that. The yields are presented as distribution of yields at these different planting options. Future developments are going-on to personalize more the system so that the user can input fertilizer scenario, and be able also to apply seasonal climate forecast, and link to the 25 sensor nodes to simulate current plant conditions given a management scenario. In this way, the user can be informed better on how to manage their sources of vulnerabilities in their fields.

\section{Keywords}

agriculture; field sensor network; Sensor Observation Service; decision support; crop simulation; data assimilation; climatological variability; DSSAT

\section{INTRODUCTION}

As the population grows and the standard of living of people improves, the demand for food will increase dramatically. Although the production of crops is expected to increase due to improve technologies and meet the demand of the world, there are a lot of uncertainties involved due to factors like climate change, conversion of food crops to biofuels, water resources availability and distribution, etc [1]. The general trend of increasing food supply does not guarantee local availability of food as well as possible proofing of catastrophic shocks that may be caused by extreme weather events, e.g., floods and droughts. Improving the efficiency of agricultural production as well as reducing risks caused by climate variability and change are important for farmers and finally for ensuring food security.

Precision farming based on detail geospatial information is a proven approach to increase yield while reducing the cost of fertilizer and other resources. Optimized agricultural practices at a meter to decimeter resolution can achieve higher and more uniform yields. In addition, soil analysis, in-situ sensing to remote sensing technology and information technology (IT) are essential tools that enable precision agriculture. 
Climatic extremes such as drought and long dry-spells affect agricultural production tremendously. With global climate change, local weather patterns have varied as well. For example, the minimum temperature in our study area in Japan has raised $4.8^{\circ} \mathrm{C}$ in 120 years, which impacted agricultural production in the region. The occurrence of extreme events as well as change in climate impose risks to agricultural productions, which should be taken into account in the decision making process both for tactical and strategic decisions.

Information provided to farmers in an integrated manner, such as real-time status of their farmland, weather data, as well as impact of different agricultural practices and climatological scenarios may help their decisions e.g., in strategic crop management and planning and their daily agricultural practices to maintain their crops to the best condition possible.

A service platform built on geospatial data infrastructure is being developed, tested and deployed in order to effectively integrate multi-scale field and remote sensing data that are provided to the users in user friendly forms, e.g., time series plots, maps, tables, and with the capability to link those information with the webbased crop simulation model to explore scenarios given past and current climate, crop, soil and management practices. The webbased crop model was combined with a weather generator, which is a powerful tool for understanding uncertainty due to climate and management strategies and including them in their decision making process. The users can evaluate farming options under the condition when future weather is unknown. The capability of using seasonal climate forecast is still being integrated in the system.

\section{STUDY AREA}

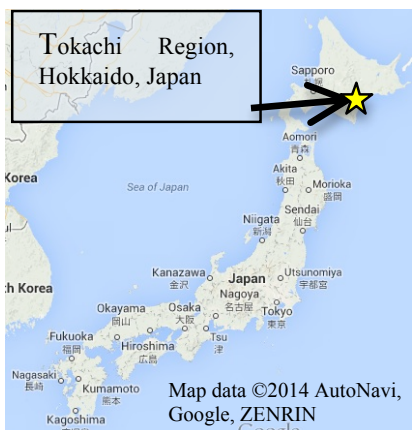

Figure 1. Tokachi Region

Our study area is located in Tokachi region, Hokkaido, Japan (Fig.1). Main crops in the region are wheat, potato, sugar beat and beans. Total area of the cropland in Tokachi is 255,200 ha that occupies $5.5 \%$ of total cropland in Japan. Number of farmers in the region is 6,743 . Average farmland per one farmer is 38 ha. The area is famous in Japan for largescale mechanized agriculture.

The total revenue of the all crops in the region was 120.3 billion Yen, and the average income per farmer was 12.1 million Yen in 2008FY [2]. The climate is cool with its annual average temperature $6.8^{\circ} \mathrm{C}$. Annual rainfall is approximately $888 \mathrm{~mm}$ [3].

\section{FIELDTOUCH AGRICULTURAL INFORMATION SERVICE PLATFORM}

An agricultural information service platform called FieldTouch is being developed, deployed and tested in order to provide farmers with useful information for their strategic and tactical decisions in their farms e.g., more precise fertilizer management (fig.2, 3). Our target users are mainly individual farmers. But we also include food industries that have contract farms, and any other stakeholders who are involved in food supply chains. The service platform is built on geo-spatial data infrastructures that archives multi-scale sensor data from ground field sensor network to satellite images. Several components in the application layers obtain geo-spatial data via standard web services and perform analysis, visualizations and interact with users for their decision making process. This kind of system can help an agricultural expert to advise the farmer better compared to using traditional systems of soil sampling and data collection.

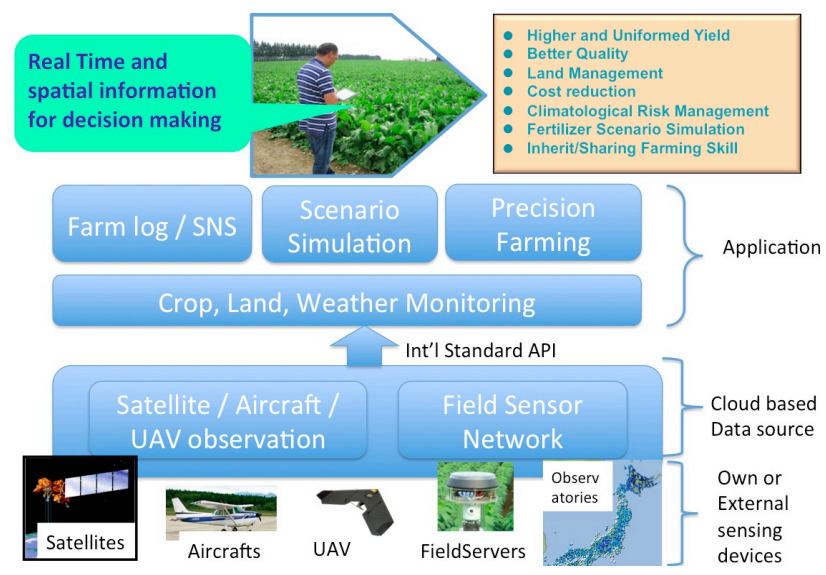

Figure 2. Overview of FieldTouch Agricultural Information Service Platform

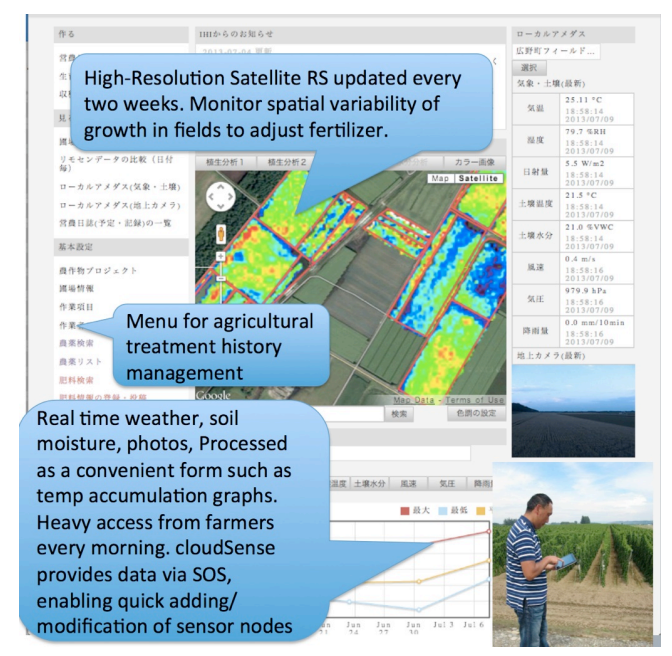

Figure 3. User interface of FieldTouch

\section{showing updated satellite images and sensor data}

The information generated from this system includes records of agricultural practices as input by the farmers (bookkeeping) through the user-interface of the system, weather data, field sensor data, satellite images processed and analyzed to show conditions of crops at the date of acquisition. This high resolution remote sensing data can show areas that may be suffering from nutrient deficiency and water stress that vary in space and time and as a result the farmer can conduct visual inspection and perform the necessary intervention to improve farm performance. The webbased crop simulation system, which will be discussed later, contains calibrated crop model parameters derived from long-term agronomic experiments, evaluates crop performance based on weather scenarios and agriculture practices. Farmers can obtain these information and optimize their farming practices such as 
varying application of fertilizer from a place to place in order to attain higher and uniformed yield and of better quality while reducing the cost of operation.

In this current version, crop simulations are performed for evaluating different farming options under various weather scenarios generated from climatology; 100 weather realizations generate 100 yield data that represents the probability distribution of yield, which is valuable information to evaluate and manage the risks from possible weather variability. With the future inclusion of seasonal climate forecast and more personalized options e.g., adjusting fertilizer applications, the users can see how a crop management practice will impact their final yields. A concurrent study is being conducted to evaluate the utility of the system through surveys and regular seminars with the participating partners. Result of that study will be reported in another paper.

\section{MULTI-SCALE SENSOR DATA}

Multi-scale sensor data from satellite, aircraft, UAV (fig.4) and field sensor data were acquired and integrated. Currently we update satellite images of farms using RapidEye every two weeks. RapidEye is a constellation satellite system with 5 identical satellites, that provides high-resolution $(6.5 \mathrm{~m})$ and high-frequency data (every day by observation request). The project operates a Cessna aircraft equipped with a multispectral camera. We fly swinglet and eBee UAV that acquire RGB and NIRGB images, then generate mosaics of them as well as 3D topographic data of farms. The ground resolution of the image from UAVs is set $5 \mathrm{~cm}$ to $8 \mathrm{~cm}$ in order to identify the detail states of crops.
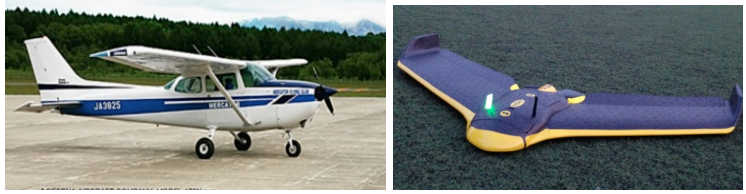

Figure 4. Aircraft and UAV that acquires high-resolution multi-spectral images.

We acquire field sensor data from 25 field sensor nodes every 10 minutes or hourly. We also acquire model-derived weather data from NIAES (National Institute for Agro-Environmental Science, Japan) that is based on AMeDAS (Automated MEteorological Data Acquisition System) data of JMA (Japanese Meteorological Agency). AMeDAS is observing limited number of weather variables. NIAES calculates various climate variables required for running crop models out of AMeDAS data [4].

\section{FIELD SENSOR NETWORK AND INTEROPERABILITY}

Field sensor network is an emerging technology to distribute more sensors than ever and collect real-time data, then provide the data via the Internet. Fieldserver is a typical platform being applied in monitoring agriculture fields [5]. In our field, we have several types of field sensor platforms including fieldserver, some of which are operated by ourselves, and others are by local governments (fig. 5 ).
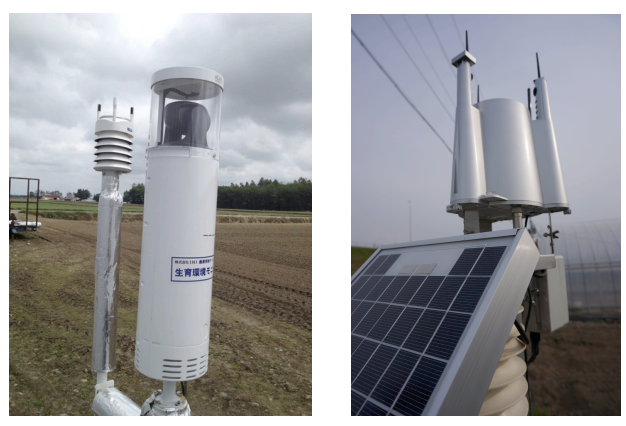

Figure 5. Field sensor platforms in the project area. Left is a fieldserver. It has weather station, camera and soil sensors. Right is a weather station operated by Obihiro city hall.

In order to provide information services especially when we integrate various data sources, interoperability of data and system is important. We have been developing a sensor backend service [6] on cloud called cloudSense (fig. 6) to ensure easy connection of field sensor to database and interoperability based on SOS (Sensor Observation Service). SOS is one of the SWE (Sensor Web Enablement) specifications published by OGC (Open Geospatial Consortium). This API allows applications to dynamically query sensor metadata and data, which makes it possible for us to add and modify sensors and automatically reflect the change in sensor configuration to FieldTouch without program modification. All field sensor data including 25 local sensor nodes, as well as NIAES-JMA data are archived on cloudSense and serve to the applications via SOS. By this technology, the challenge of system integration of multiple variables at multiple scales and standards is minimized.

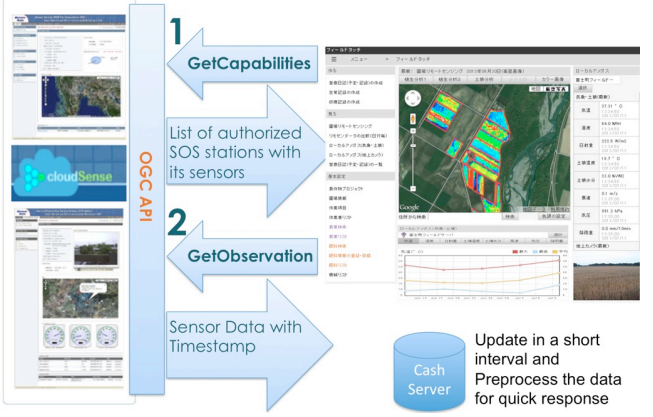

Figure 6. Applications request sensor metadata and sensor data through OGC's standard API - Sensor Observation Service.

\section{CROP MODELING AND SCENARIO SIMULATION}

One of the unique functionalities we are now implementing is evaluation of weather scenarios by crop modeling and successive simulation (fig. 7). The Decision Support System for Agrotechnology Transfer - Cropping System Model (DSSAT-CSM) simulates growth, development and yield of a crop growing on a homogeneous land area, under prescribed or simulated management practices, as influenced by the dynamics of solar radiation, temperature, and soil water, carbon and nitrogen [7]. Farmers will be able to see the impact of climate variability to expected yield in the form of yield distributions updated at any 


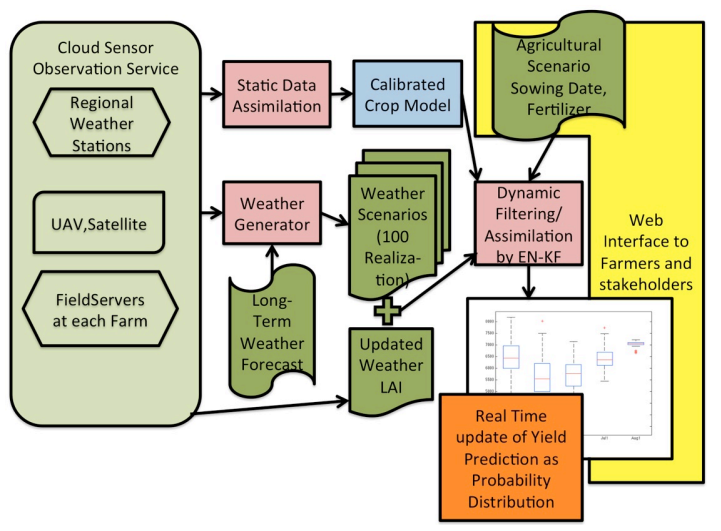

Figure 7. Crop modeling, simulation system. Data is provided to assimilation and weather generator by OGC's standard API.

period during the growing season. We calibrate DSSAT crop model by data assimilation $[8,9]$ using past yield data and sensor data. Genetic algorithm (GA) is linked with DSSAT to estimate the genetic coefficients of a local wheat variety in the study area. The objective function is based on weighted multiple functions of yield, anthesis date, maturity date and leaf area index. We describe the GA search process here (fig. 8).

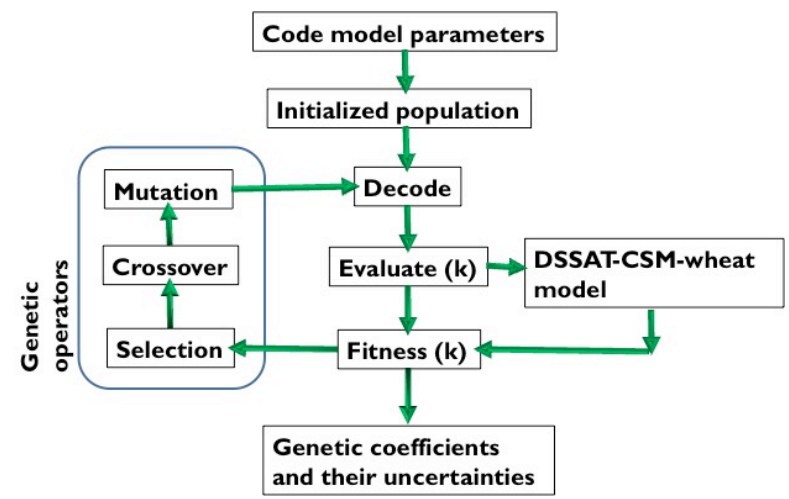

Figure 8. Genetic algorithm linked with DSSAT

GAs are powerful search techniques combining the survival of the fittest mechanism with a structured yet randomized information exchange to search for solutions of complex search and optimization problems $[10,11]$. The search spaces of the unknown parameters are discretized into finite lengths and then coded as sets of binary substrings to form a string structure called a chromosome. The procedure starts by randomly generating a set of chromosomes (called a population) serving as starting search positions at the search surface. The chromosomes are individually evaluated to determine their suitability based on a given fitness function. The chromosomes then go through the process of selection, crossover, and mutation. Based on their fitness, they compete to be selected, mate, and reproduce for the next generation. During selection, the fitter chromosomes survive and the weaker chromosomes die. The selected chromosomes then randomly mate to exchange genetic information through the process of crossover and produce offspring. The resulting new chromosomes are subjected to mutation to infuse fresh genetic materials for the new generation and to restore certain genetic characteristics that were lost due to degeneracy. The processes of selection, crossover, and mutation are repeated for many generations until the best possible solution is achieved. This solution is the fittest chromosome that evolved after many generations. The genetic coefficients of DSSAT wheat model are coded as chromosomes in this case.

Sample calibrated yields (fig. 9) show the capability of the Genetic Algorithm to fit the observed yield. We should note however that the derived model parameters should capture actual processes in plant's growth.

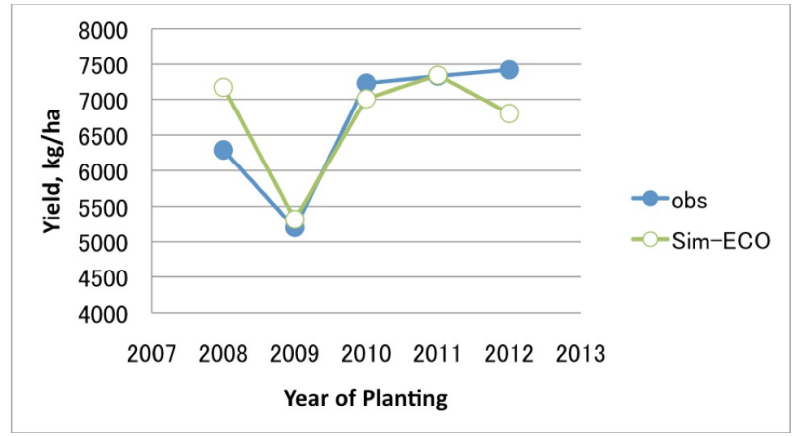

Figure 9. Calibrated yields by Genetic Algorithm

obs: observed, Sim-ECO: simulated

Once calibrated, we can now run the crop model for the local variety and perform scenario analysis. Scenario analysis can be done by running combinations of planting, fertilizer management at given a climate condition and gauge the best one for such a condition. Likewise, stochastic weather generator is very useful to generate weather scenarios. A weather generator is a structured random number generator used to generate sequences of weather variables. It is composed of two sub-models, rainfall and nonrainfall models. The rainfall model has two sub-models, one for rainfall occurrence and rainfall amounts. The non-rainfall model is used to generate temperature and solar radiation [12]. At the beginning of the growing season, we do not have weather data for the rest of the growing season. The weather generator is used to generate weather realizations. As the season progresses, more observed data are observed from sensor and the rest of the growing season with generated weather. We generate 100 weather scenarios by analyzing historical weather data and run the model.

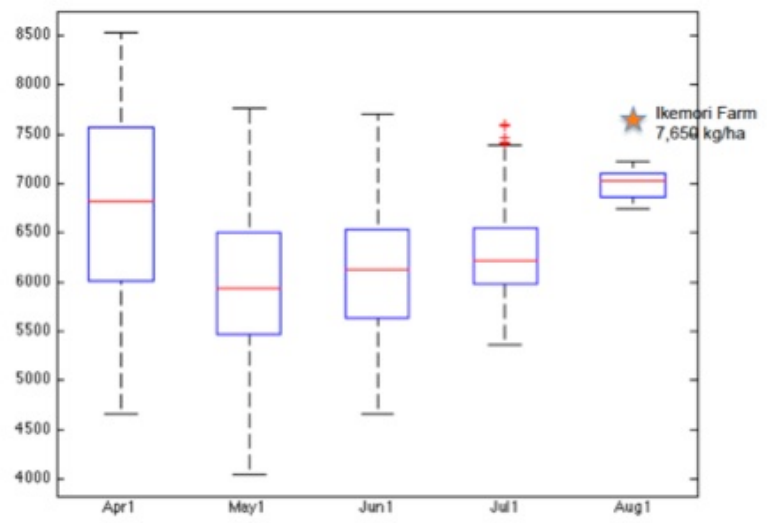

Figure 10. Yields simulated by updating weather scenarios showing how yield prediction uncertainty decreases as the growing season progresses using boxplots. 
The yields simulated at the beginning of the growing season usually have higher uncertainty. But as newly observed weather data replaces the weather scenarios in the course of the growing season the uncertainty in weather scenario is reduced, and we update the expected yield successively (fig. 10). This mechanism allows also the updating of fertilizer management in the growing season.

This updating mechanism can also be done for the plant and soil parameters using a dynamic filter (fig. 7) to improve more performance, such as updating leaf area index and soil moisture by sensor observations. This kind of updating mechanism corrects the prediction errors associated to model.

We implemented a web-based DSSAT wheat model called Tomorrow's Wheat (TMW) (http://tesla.isc.chubu.ac.jp) that shows the basic idea of the simulation system (fig. 11). TMW framework was based on Tomorrow's Rice (TMR) but had been enhanced [13]. TMW collects the historical weather data from CloudSense via OGC's SOS (Sensor Observation Service). The original data source is NIAES's agro-weather data derived by model calculation from AMeDAS data. Currently only Memuro and Obihiro data is provided. The cultivar parameters of Kitahonami variety was calibrated against yield and field observation (fig. 9). TMW simulates the expected yields at given planting, soil and cultivar characteristics.

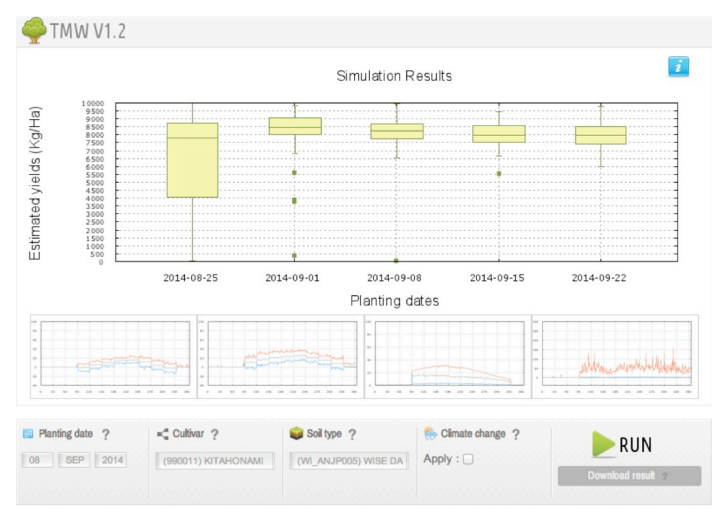

Figure 11. Yield simulation for different planting dates. 100 of weather scenario are generated by historical climatology. Expected yield is shown as a distribution using boxplots.

\section{CONCLUSION}

In this paper we presented a service platform that integrates multiscale sensing data, drives crop model calibration and simulation that can generate useful information for farmer's decision making, be it tactical or strategic in nature. The inclusion of a weather generator allows the user to evaluate uncertainty of weather conditions on the agricultural production system and thus be able to simulate better agricultural scenarios that can provide a better performance. Combination of standard web services from geospatial infrastructure and crop modeling and simulation has advantage for flexible operation of the system. This mechanism is particularly efficient when we expand our service to other stakeholders by adding more application sub system in this platform.

\section{ACKNOWLEDGMENTS}

We would like to thank Prof. Masayuki Hirafuji and his team, NARO (National Agriculture and Food Research Organization) for supporting us by valuable information. We would like to thank Dr. Tsuneo Kuwagata, NIAES (National Institute for AgroEnvironmental Sciences, Japan) and Obihiro City Hall for allowing us to link their internet weather data service to our SOSbased sensor service.

\section{REFERENCES}

[1] Nikos Alexandratos and Jelle Bruinsma, Global Perspective Studies Team, World Agriculture Towards 2030/2050, The 2012 Revision, FAO

[2] Hokkaido Bureau, Ministry of Land, Infrastructure, Transport and Tourism of Japan, http://www.ob.hkd.mlit.go.jp/hp/agri/pr_n/aramashi.pdf

[3] Japan Meteorological Agency, http://www.jmanet.go.jp/obihiro/obihiro_four_seasons.pdf

[4] MeteoCrop DB: an agro-meteorological database coupled with crop models for studying climate change impacts on rice in Japan, T. Kuwagata, M.Yoshimoto, Y. Ishigooka, T. Hasegawa, M. Utsumi; M. Nishimori, et al., Journal of Agricultural Meteorology; ISSN:0021-8588; VOL.67; NO.4; PAGE.297-306; (2011)

[5] M. Hirafuji, T. Fukatsu, H. Hu, H. Yoichi, T. Kiura, S. Ninomiya, M. Wada, H. Shimamura, Field Server: Multifunctional Wireless Sensor Network Node for Earth Observation, pp.304, SenSys'05 Proceedings of the Third International Conference on Embedded Networked Sensor Systems, November 2-4, 2005, San Diego, California, USA

[6] K. Honda, A. Shrestha, A. Witayangkurn, R. Chinnachodteeranun and H. Shimamura, Fieldservers and Sensor Service Grid as Real-time Monitoring Infrastructure for Ubiquitous Sensor Networks. Sensors (ISSN 1424-8220), 9, no. 4: 2363-2370., doi:10.3390/s90402363, 2009

[7] Jones, J.W., Hoogenboom, G, Porter, C., Boote, K.J., Batchelor, W.D., Hunt, L.A., Wilkens, P.W., Singh, U., Gijsman, A.J. and J.T. Ritchie. 2003. The DSSAT Cropping System Model. Europ. J. Agronomy. 18: 235-265.

[8] A.V.M. Ines, K. Honda, A. Yui, A Crop Simulation System for Integrating Remote Sensing and Climate Information to Reduce Model Uncertainty in Crop Yield Assessments, American Geophysical Union(AGU) 2012 Fall Meeting, GC13B-1086, 3-7 Dec, San Francisco, USA, 2012

[9] S. Charoenhirunyingyos, K. Honda, D. Kamthonkiat, A.V.M Ines, Soil moisture estimation from inverse modeling using multiple criteria functions, Computers and Electronics in Agriculture , 75, 278-287, ISSN 0168-1699, 2011

[10] Holland, J. H. Adaptation in Natural and Artificial Systems, Univ. of Mich. Press, Ann Arbor. 1975

[11] Goldberg, D. E. Genetic Algorithms in Search and Optimization and Machine Learning, Addison-Wesley, Washington, D. C. 1989

[12] Hansen, J.W. and A.V.M. Ines, Stochastic disaggregation of monthly rainfall data for crop simulation studies. Agricultural and Forest Meteorology. 131: 233-246, 2005

[13] Teeravech, K., Honda K., Ines, A.V.M. and R. Chinnachodteeranun. 2013. Tomorrow's Rice Ver 1 : Rice yield simulation and prediction by DSSAT on web. Burapha University International Conference Proceedings 